\title{
Automatic Taxiing Direction Control System for Carrier-Based Aircraft
}

\author{
Mariusz Krawczyk, Cezary Szczepański, Albert Zajdel
}

This paper solves the problem of automatic taxiing direction control of carrier-based aircraft. On modern aircraft carriers, taxiing aircraft either propel themselves using their own engines or are towed by specialised tugs, which requires dedicated personnel and assets. The automatization of this process would simultaneously increase aircraft flow and decrease the number of personnel and assets required. The key challenge in the automatization of this type of process is the development of an automatic control system capable of performing the requisite tasks, which our researchers managed to do. First, the specific conditions of taxiing on-board carriers were analysed and modelled. The model of a fixed-wing aircraft best suited to this purpose was identified and the proper method of automatic control - ADRC - chosen. The algorithm used in the method to facilitate effective direction control of a taxiing aircraft was formulated and extensively tested. The results of automatic taxiing simulation for F/A-18 aircraft have been presented. The conclusion is that the ADRC type control algorithm can ensure effective automatic control of taxiing aircraft.

\section{KEY WORDS}

$\sim$ Automatic taxiing control

$\sim$ Automatic flight control

$\sim$ Aircraft taxiing

\section{INTRODUCTION}

Taxiing is the movement of an aircraft on the ground before initiating the take off procedure, i.e. preceding the take off run, and after the landing manoeuvre, i.e. after the speed drops below the limit defined as the end of a landing run. The term is most frequently used to describe motion on the ground, or water in case of hydroplanes, and hovering over the runway in case of helicopters equipped with landing skids. Motion along the deck of an aircraft carrier (CVN - aircraft carrier (nuclear propulsion)) or a smaller assault ship (LHD - landing helicopter deck) suitable for fixed wing short take-off and vertical landing (STOVL) aircraft is a special case of taxiing (USA DoD, 2019) due to three reasons. Firstly: taxiing along the deck of an aircraft carrier, or of another sea vessel involves dynamic interaction. Secondly: the ship's speed and weather conditions at sea, characterised by frequent winds of considerable speed, have a direct impact on aerodynamic forces and torques affecting the object (Yangang et al., 2013). Thirdly: the limited surface of a navy ship's deck (in comparison with even the smallest dry land airports) aggravates the take off/landing process, making it more complex and requiring the flawless cooperation of numerous specialized teams divided into seven functional groups.

The basic layout of an aircraft carrier is presented in Figure 1. The recognized definition of taxiing suggests that this process commences once an aircraft is brought to the deck by an elevator. The aircraft is then manoeuvred either to a parking place, or directly to start place containing one of the four steam or electromagnetic (Nimitz/Ford class carriers) catapults. After landing assisted by the Arresting Gear Pendants system, the aircraft either taxis to one of the four available elevators or to a parking place, to be prepped for the next flight.

Considering the conditions characteristic of taxiing on the deck of a navy ship, the challenges of optimisation of this stage of flight may be concluded to be similar to those faced by airportbased aircraft, namely: 


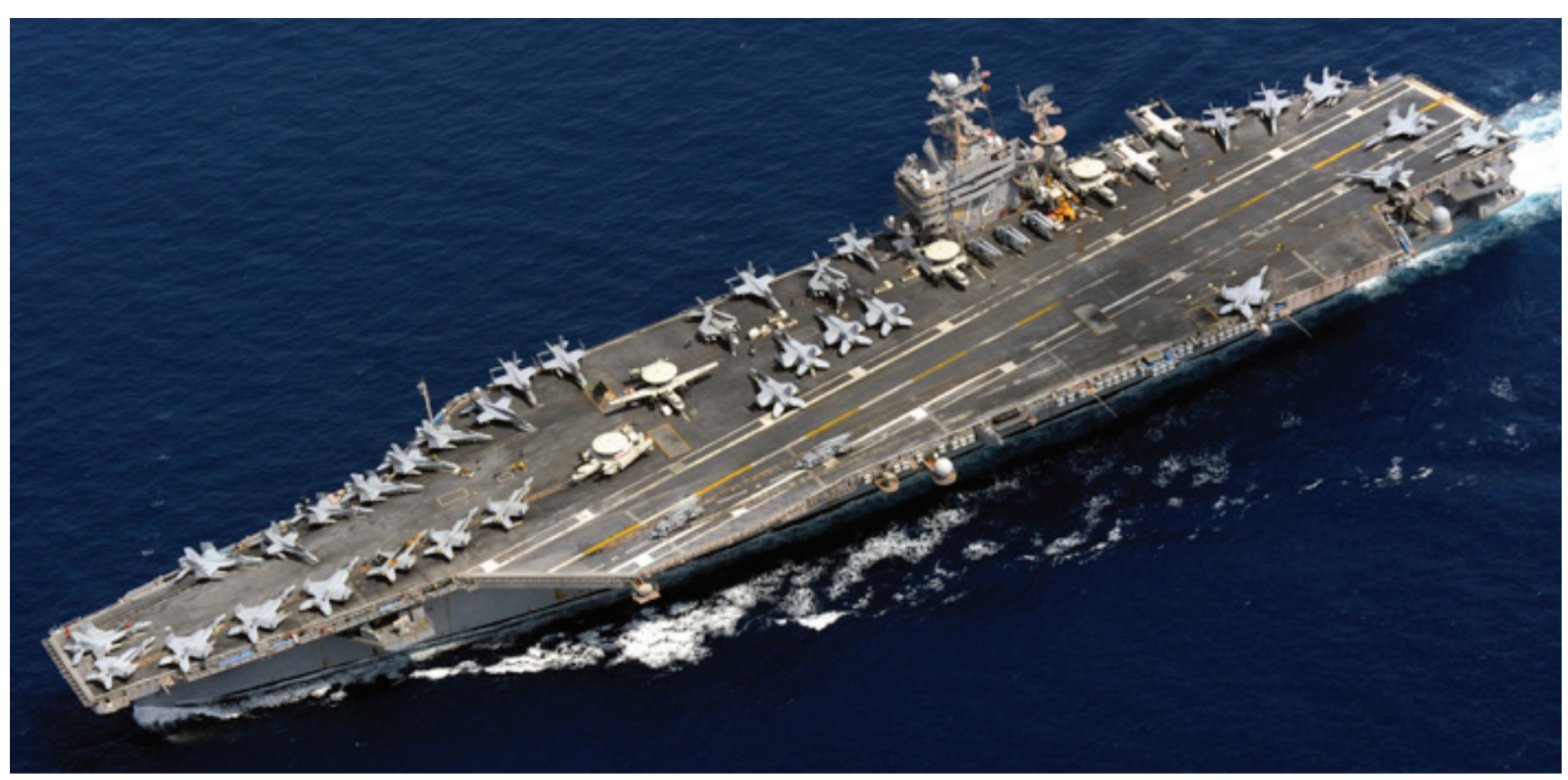

Figure 1.

Nimitz class aircraft carrier (Pixabay). traffic;

the decreasing capacity of airports due to increasing air - the need to open civil airspace to unmanned aircraft operations, especially military in character, limiting access to airports;

- $\quad$ problems with the identification of and staying on the right taxiway in case of restricted visibility, especially in oversized airports;

- $\quad$ an increased probability of accidents during taxiing in restricted visibility conditions;

- excessive pilot workload in case of intensive traffic in the airport;

- the two pilot cockpit crew requirement due to the complex handling of some types of aircraft.

Automatic taxiing control systems, having the potential to change the current status quo in the engineering domain, are a relatively new type of aircraft control systems. Until now, they have not gone beyond the concept, project and simulation stages, where the issues of control algorithms, control rules and modelling of taxiing aircraft motion still plague some areas of development.

An aircraft is far from being the "optimal" vehicle for taxiing. While aerodynamic drag minimization is a goal shared by aircraft and car designers, when it comes to lifting force, their goals are quite opposite. Racing car (e.g. Formula One car) designers focus on achieving maximum aerodynamic downforce on a vehicle moving on a racetrack. On the other hand, aircraft designers strive to get maximum lifting force, affecting required runway length. In case of a crosswind, the yawing moment and crosswind force may achieve considerable values, especially in aircraft having a broad side projection and/or a large vertical stabiliser. However, it is the forces and torques generated in the tyre ground contact zone that have the greatest impact on an aircraft's motion. Therefore, the modelling of taxiing aircraft motion has to be a combination of classical aircraft modelling and wheeled vehicle modelling.

\section{CONTROL OBJECT MODEL}

The McDonnell Douglas F/A-18 Hornet, presented in Figure 2 , is a twin-engine, supersonic, all-weather, carrier-capable, multirole combat jet with a three-point landing gear with a front swivel wheel. The main wheels are equipped with disc brakes. The maximum take-off weight is $m=16769 \mathrm{~kg}$, wingspan is $I=12,3$ $m$, their lift area is $S=18,2 \mathrm{~m}^{2}$ and the mean aerodynamic chord is $c_{a}=2,91 \mathrm{~m}$.

The $O_{0} x_{g} y_{g} z_{g}$ coordinate system fixed to the moving carrier is non-inertial due to the two main factors: carrier rotation and lateral linear acceleration, resulting from the high turning rate at high advance velocity, which can reach 30 knots in a Nimitz 
class carrier. It can be easily demonstrated using only basic calculations that during the turning manoeuvre, total lateral acceleration, resulting from inertial force and the component of gravity associated with the roll angle, is approximately equal to acceleration due to change of direction by an aircraft taxiing at the speed of $5 \mathrm{~m} / \mathrm{s}$. However, in most cases, especially before take-off and after landing, the carrier maintains both course and constant advance velocity. Any unavoidable angular movements may be assumed not to exceed $1^{\circ}$. Moreover, since the mass of the carrier far exceeds the mass of the aircraft, the influence of the aircraft on the carrier is negligible, which is why the carrierfixed coordinate system $O_{0} x_{g} y_{g} z_{g}$ has been treated as inertial for mathematical modelling purposes.

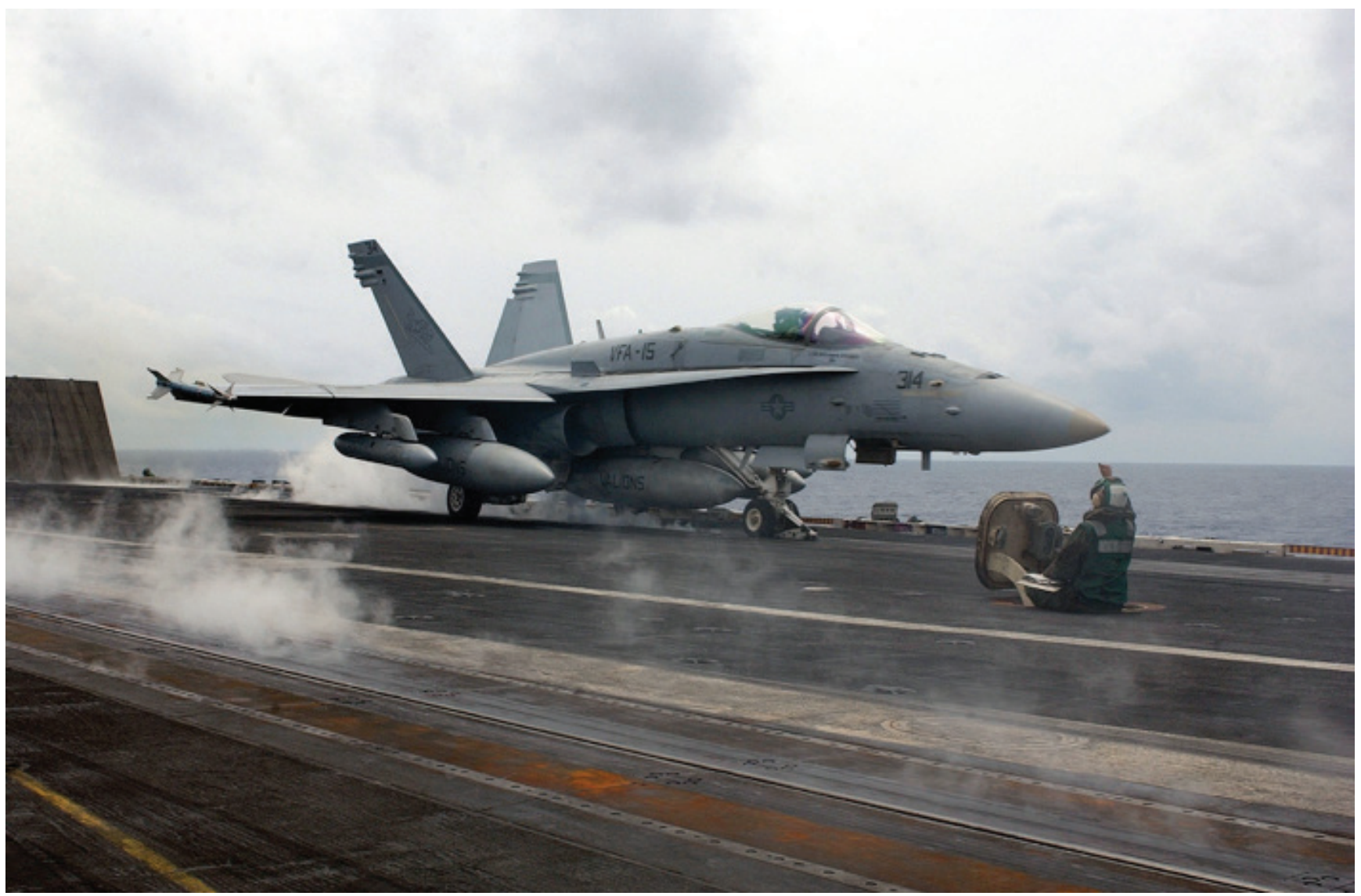

Figure 2.

McDonnell Douglas F/A-18 Hornet aircraft (Pixabay).

Considering the low contribution of control systems and undercarriage to total aircraft weight, the following assumptions have been made in the mathematical modelling of F/A-18 taxiing: an aircraft is a rigid body, has the geometric and mass symmetry plane $O x z$ of the aircraft coordinate system $O x y z$, originating in the center of aircraft mass. The Newton-Euler formula has been adopted for the formulation of F/A-18 aircraft motion dynamics equations. The following equations have been developed:

$m V+m \Omega V=F$

$J \Omega+\Omega J \Omega=M$ where: $\mathrm{m}$ - constant aircraft mass, $\boldsymbol{F}=\left[\begin{array}{lll}X & Y & Z\end{array}\right]^{T}$ - force and $\boldsymbol{M}=\left[\begin{array}{lll}L & M N\end{array}\right]^{T}$ - moment acting on aircraft, $\boldsymbol{\Omega}=\left[\begin{array}{lll}P & Q\end{array}\right]^{T}$ and $\boldsymbol{V}=[U \vee W]^{T}$ vectors properly: angular and linear velocities of aircraft in the aircraft coordinate system, and

$$
J=\left[\begin{array}{ccc}
I_{x} & 0 & -I_{x z} \\
0 & I_{y} & 0 \\
-I_{x z} & 0 & I_{z}
\end{array}\right]
$$


is the constant inertia matrix, including the existence of an aircraft symmetry plane $O x z$. The above equation system is derived from the well-known (Stevens et al., 2016) and (Cook, 2007) kinematic equations, facilitating the calculation of aircraft orientation angles (Euler angles) $\Theta, \Phi, \Psi$ and aircraft location $x_{g^{\prime}} y_{d^{\prime}} z_{g^{\prime}}$ in the assumed, inertial reference system $O_{0} x_{g} y_{g} z_{g}$.

Eliminating two complementary systems, i.e. the thrust control system and the breaking control system, is useful for automatic taxiing direction control system integration purposes. In equation systems (1), this simplification allows us to assume that the forces and moments of forces generated by the aircraft power plant, breaking system and tire friction are equalised. In this case, the following forces and moments of forces have an effect on aircraft movement: aerodynamic forces $\boldsymbol{F}_{a}$ and moments of forces $\boldsymbol{M}_{a^{\prime}}$ undercarriage forces $\boldsymbol{F}_{q}$ and the force of gravity $\boldsymbol{F}_{c}$.

During the aircraft taxiing phase, the occurrence of a nonzero angle of flow in the Oxy plane depends on two factors: wind and wheel slippage, and is equivalent to the sideslip angle during non-stationary flight. By analogy, this angle is called slip angle $\beta$. Considering that aircraft velocity during taxiing is comparable to or even lower than wind velocity, the value of the resulting slip angle $\beta$ can range between $-180^{\circ}$ and $180^{\circ}$. There is a substantial difference between the taxiing phase and the steady flight phase when the values of slip angles vary by only a couple or many degrees.

The aerodynamic forces and moment of force coefficients have been calculated from wind tunnel test data and CFD calculations (Placek et al., 2017.) Aircraft flow direction was determined using slip angle $\beta$ and local angle of attack $a_{p}$. Local angle of attack $a_{p}$ is the angle between the aircraft flow vector and the Oxy plane. These angles can be calculated as:

$\beta=\tan ^{-1}\left(\frac{V_{a}}{U_{a}}\right)$

$a_{a}=\tan ^{-1}\left(\frac{W_{a}}{\sqrt{U_{a}^{2}+V_{a}^{2}}}\right)$

where: $U_{d^{\prime}} V_{d^{\prime}} W_{a^{\prime}}$ are the components of aircraft flow resulting from aircraft motion and wind velocity.

These aerodynamic coefficients allow us to calculate both forces directly affecting aircraft motion and the component of the pressure force of each undercarriage wheel to determine friction. The chosen aerodynamic coefficients, having a substantial effect on aircraft taxiing, $c_{y} c_{z^{\prime}} c_{m^{\prime}} c_{n}$ have been shown in the Figure 3.
The influence of the F/A-18 aircraft's three-leg undercarriage with front wheel has been taken into account by incorporating forces $\boldsymbol{F}_{g_{n} z}$ for $n=1,2,3$, generated by each of the three undercarriage legs, into the model. They have been modelled as the spring-damper system (Baarspul, 1990):

$F_{g_{n} z}=-k_{n} \delta_{g_{n} z}-c_{n} \delta_{g_{n} z}$

where: $k_{n}$ - elasticity coefficient, $c_{n}$ - dumping coefficient, $\delta_{g_{n} z}$ - vertical deformation of the undercarriage element.

The values of vertical forces generated by each of the aircraft's legs allow us to calculate the side force generated at the contact point of each tyre and the ground, using the following function, depending on tyre type:

$F_{g_{n} y}=F_{g_{n} y}\left(\zeta_{n^{\prime}} F_{g_{n} t^{\prime}} \tau\right)$

where: $\tau$ - coefficient depends on the condition of the taxiway, scaling the side force on the wet/icy/snow covered taxiway in comparison with the dry taxiway (Krawczyk et al., 2019), $\zeta_{n}$ - tyre slip angle evaluated for each wheel,

$$
\begin{aligned}
& \zeta_{1}=\tan ^{-1}\left(\frac{V+R a}{U}\right)-\delta_{n} \\
& \zeta_{2}=\tan ^{-1}\left(\frac{V-R b}{U+R \frac{c}{2}}\right) \\
& \zeta_{3}=\tan ^{-1}\left(\frac{V-R b}{U-R \frac{c}{2}}\right)
\end{aligned}
$$

where: $\delta_{n}$ - front wheel deflection angle, $a$ - the distance between the front wheel and the projection of the aircraft's center of gravity on the Oxy plane, $b$ - the distance between main wheels, $c$-wheelbase.

The force of gravity components in the Oxyx coordinate system depends on aircraft orientation:

$F_{c}=m g\left[\begin{array}{c}\sin \Theta \\ \sin \Phi \cos \theta \\ \cos \Phi \cos \theta\end{array}\right]$ 

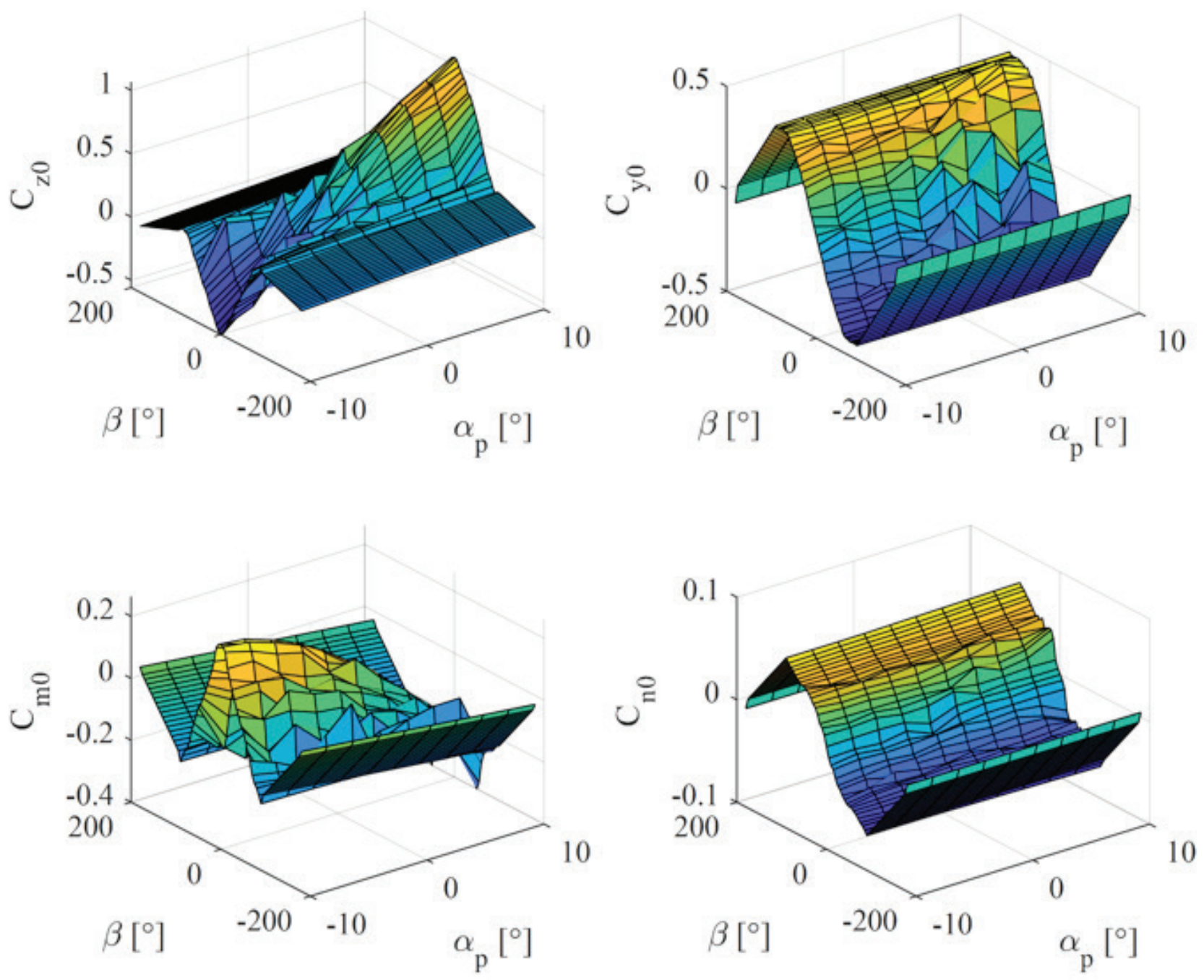

Figure 3.

Aerodynamic coefficients as functions of slip angle and local angle of attack.

\section{AUTOMATIC TAXIING CONTROL SYSTEM}

The control algorithm presented in this paper is a part of an automatic taxi control system (Zajdel et al., 2017). The proposed general structure of the system (Figure 4) is inspired by the structure of contemporary flight control systems. The system consists of a high level controller that tracks reference trajectory, the generation of yaw angle and speed reference for the low level controller. Its role is equivalent to that of the Flight Management System. The low level controller contains the control algorithm and is responsible for steering the aircraft by tracking reference values of the required quality. Its role is equivalent to that of an autopilot.

The choice of the control algorithm was based on the analysis of the known algorithms in terms of compliance with the three criteria shown in Table 1. 


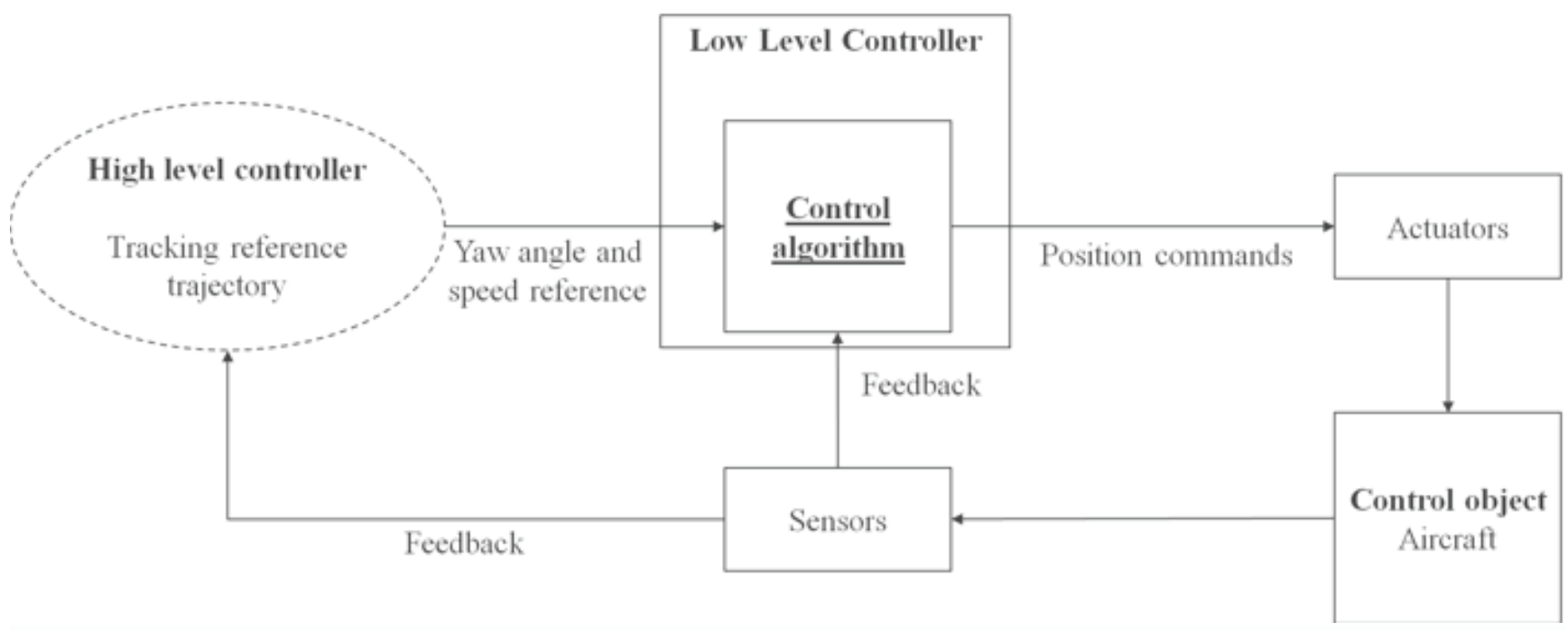

Figure 4.

General structure of the Automatic Taxiing Control System.

Table 1.

Results of control algorithm analysis.

\section{Control algorithm \\ Is robust to model uncertainties}

PID with gain scheduling

LQR

NDI

H_o

MRAC, MIAC

MPC

LPV

Backstepping

Sliding Mode

Fuzzy Logic

Neural Network

ADRC
X

$x$

X

$\mathrm{X}$

\section{Can be synthetized with} nonlinear model

\section{Does not need full state} feedback

X

X

$x$

$x+x$

$\mathrm{X}$

$x$
$x$
$x$
$x$

$\mathrm{X}$

$x+x$

$X$

$x$

$X$

$x$

$x$

$x$
The algorithm analysis identified four candidates meeting the criteria. The ADRC (Adaptive Disturbance Rejection Control) algorithm does not suffer from issues like chattering in connection with sliding mode control, neural network training process and lack of rules for fuzzy set formulation (Zammit \& Zammit-Mangion, 2014a/b). The ADRC was thus chosen as the algorithm to be used in the automatic taxiing direction control system.

The main idea behind the ADRC is to compensate disturbances by introducing an error between model output and extended state observer (ESO) output, called total disturbance in the internal feedback loop. The ESO structure reduces the 


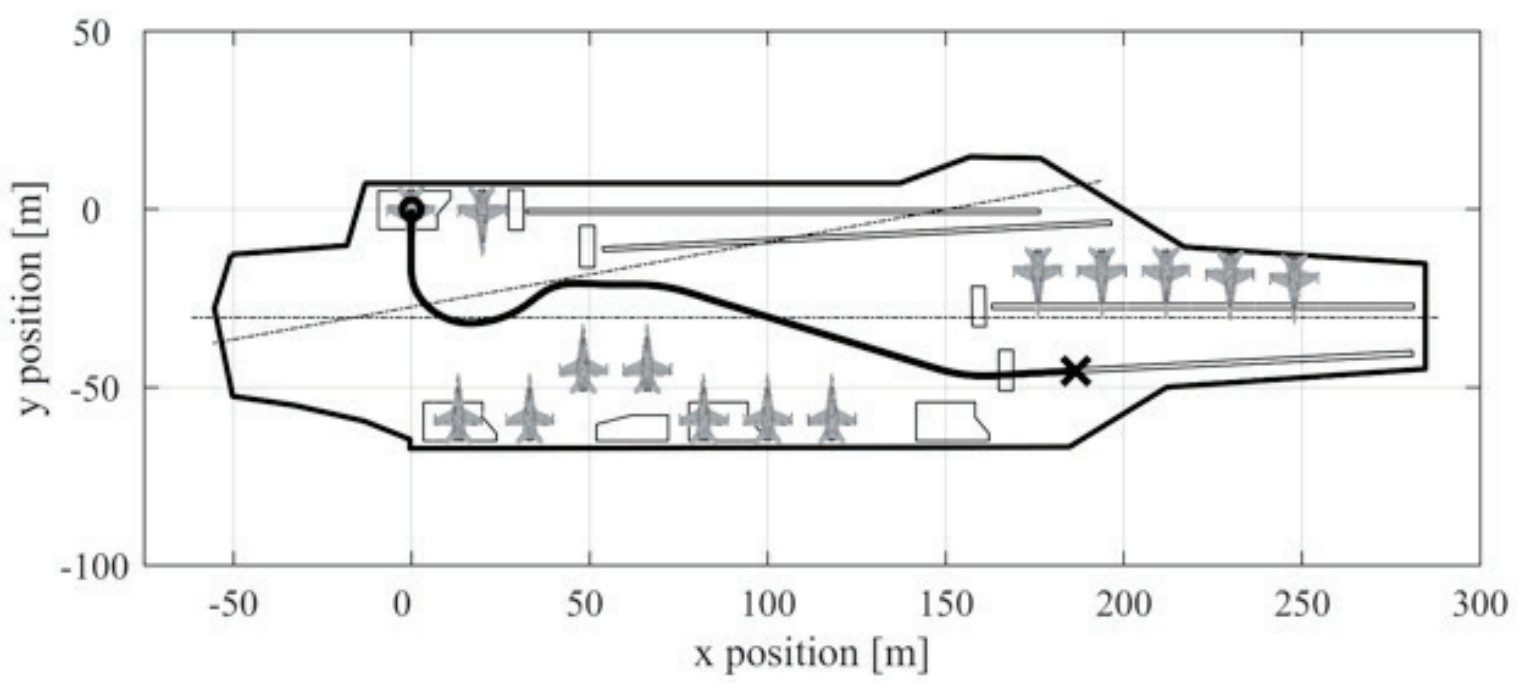

Figure 5 .

Aircraft trajectory during automatic taxiing using ADRC direction control algorithm.

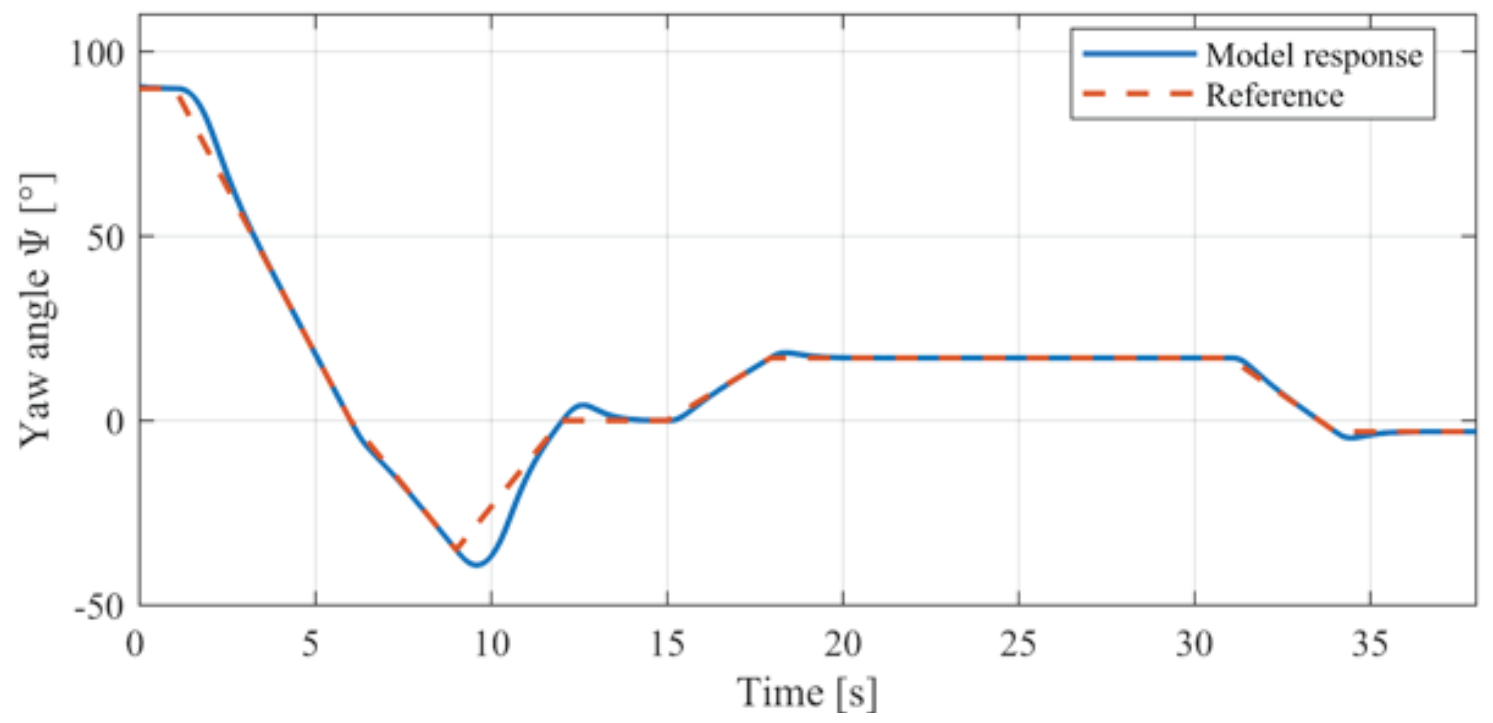

Figure 6.

Yaw angle model response and reference yaw angle - tracking performance of ADRC direction control.

model to a double integrator which includes total disturbance as an extended state. This approach ensures robustness in the presence of model uncertainties and simplifications (Han, 2009), (Gao, 2006).

The ADRC was applied as a directional control algorithm that tracks the reference yaw angle by turning the nose wheel of the F/A-18 aircraft model presented in the preceding chapter. It was tested in a taxi scenario on the carrier deck in the arrangement called "flex deck" - used when take-offs and landings are performed simultaneously. The waist and the stern of the ship are used for landing, whereas bow cat 1 is used for take-offs (The Arrangemet..., 2019), (NATC, 2014). 
Figure 5 illustrates the resulting trajectory of the aircraft taxiing from elevator 4 to catapult 1 by crossing the landing area and manoeuvring between parked F-18 aircraft. Figure 6 shows the yaw angle tracking performance of the ADRC algorithm. The nose wheel command signal and nose wheel angular position are shown in Figure 7.

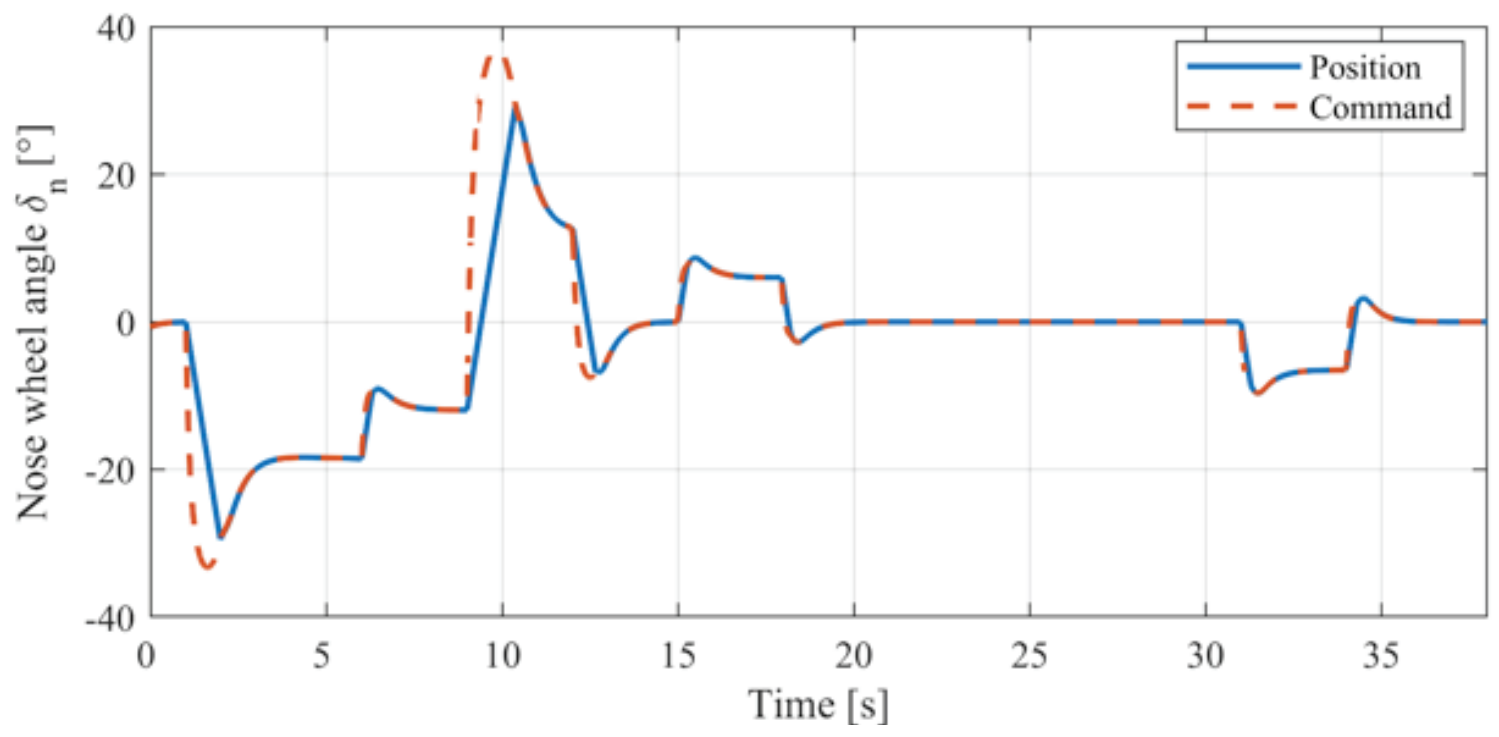

Figure 7.

Nose wheel angular position commanded by the ADRC directional control and its measured position.

\section{CONCLUSIONS}

The presented results of simulation tests suggest that the ADRC control algorithm can be successfully used in a carrier-based aircraft automatic taxiing control system. The aircraft tracked the reference yaw angle with satisfactory performance, as the aircraft followed the desired taxi route. In the sharpest turns on the simulated taxiing route, the front wheel servomechanism speed saturated for a few seconds. The yaw angle tracking performance in these moments could be improved by using faster front wheel servomechanism.

Taking into account previous research (Krawczyk et al., 2019), (Zajdel et al., 2017) on automatic taxiing direction control system for ultralight aircraft showed the ADRC algorithm to also be suitable for use in the said system in aircraft having significantly different parameters.

The automatic taxiing of aircraft, particularly unmanned, on the airfield or carrier deck, is a challenge facing present-day aeronautic specialists. The introduction of such systems requires the solving not only of technological, but also of organisational, legal and operational issues connected with this phase of aircraft operation.

\section{REFERENCES}

Baarspul, M., 1990. A review of flight simulation techniques. Progress in Aerospace Sciences, 27(1), pp.1-120. Available at: http://dx.doi.org/10.1016/03760421(90)90006-6.

Cook MV, 2007. Flight Dynamics Principles. 2nd ed. Cambridge, Elsevier.

Han, J., 2009. From PID to Active Disturbance Rejection Control. IEEE Transactions on Industrial Electronics, 56(3), pp.900-906. Available at: http://dx.doi.org/10.1109/ tie.2008.2011621.

Krawczyk, M., Szczepanski, C.J. \& Zajdel, A., 2019. Aircraft model for the automatic taxi directional control design. Aircraft Engineering and Aerospace Technology, 91(2), pp.289-295. Available at: http://dx.doi.org/10.1108/aeat-01-2018-0025.

Naval Air Training Command, 2014. Flight training instruction: CV Procedures (UMFO) T-45C. CNATRA P-816.

Placek R, Ruchała P, Stryczniewicz W., 2017. Ground effect influence on the aerodynamic characteristics of ultralight high-wing aircraft - wind tunnel tests. Journal of KONES, 24(2), pp.183-190.

Stevens BL, Lewis FL, Johnson EN, 2016. Aircraft Control and Simulation. 3rd ed. Hoboken, Wiley.

The Arrangement of Planes on the Flight Deck, 2019. Available at: https://www. navysite.de/cvn/deck.htm, accessed on: 14 May 2019. 
USA Department of Defence, 2019. Airfield and heliport planning and design. UFC 3-260-0.

Yangang, W., Weijun, W. \& Xiangju, Q., 2013. Multi-body dynamic system simulation of carrier-based aircraft ski-jump takeoff. Chinese Journal of Aeronautics, 26(1), pp.104-111. Available at: http://dx.doi.org/10.1016/j.cja.2012.12.007.

Zajdel, A. et al., 2017. Selected Aspects of the Low Level Automatic Taxi Control System Concept. Transactions on Aerospace Research, 2017(2), pp.69-79. Available at: http://dx.doi.org/10.2478/tar-2017-0016.
Zammit, C. \& Zammmit-Mangion, D., 2014. A control technique for automatic taxi in fixed wing. 52nd Aerospace Sciences Meeting. Available at: http://dx.doi. org/10.2514/6.2014-1163.

Zammit, C. \& Zammmit-Mangion, D., 2014. An enhanced automatic taxi control algorithm for fixed wing aircraft. AIAA Guidance, Navigation, and Control Conference. Available at: http://dx.doi.org/10.2514/6.2014-1300.

Zhiqiang Gao, 2006. Active disturbance rejection control: a paradigm shift in feedback control system design. 2006 American Control Conference. Available at: http://dx.doi.org/10.1109/acc.2006.1656579. 